\title{
Restraining Loose Equipment Aboard the International Space Station: The Payload Equipment Restraint System
}

\author{
Kenneth A. Smith \\ Raytheon Information Technology and Scientific Services, Marshall Space Flight Center, Alabama, USA \\ David W. Reynolds \\ National Aeronautics and Space Administration, Marshall Space Flight Center, Alabama, USA
}

Copyright @ 2003 SAE International

\begin{abstract}
As the International Space Station (ISS) grows, so do the supplies and equipment needed to support its daily operations. Each day many items must be unstowed and moved to various worksites so that they are readily available to the crew. Due to the lack of gravity, these items may become loose and float away if not restrained. The Payload Equipment Restraint System (PERS) was developed to meet the new and unique challenge of restraining loose equipment aboard the ISS.
\end{abstract}

\section{INTRODUCTION}

The ISS is a tremendously growing facility in Earth's orbit built to enhance the scientific, technological, and commercial use of the space environment. As the Station grows, so do the supplies and equipment needed to support its daily operations. Each day many items must be unstowed (Figure 1) and relocated to various worksites so that they are readily available to the crewmembers as they perform their activities. On Earth, this task is relatively simple; gravity allows the relocated equipment to stay where it is placed. Due to the lack of gravity in Earth orbit, this task is not so simple-items float away if not properly restrained. This condition is well known in the space industry and has been handled in many ways over the years. Dealing with this condition aboard the ISS offers a new and unique challenge. Unlike Skylab- and Shuttle-based labs that typically have the equipment needed to perform an activity stowed at that location, equipment aboard the ISS is stowed in many locations. As more elements are added to the ISS, such as the European Space Agency (ESA) Columbus Orbital Facility (COF) and the National Space Development Agency (NASDA) Japanese Experiment Module (JEM), the more spread out these stowage locations will become.

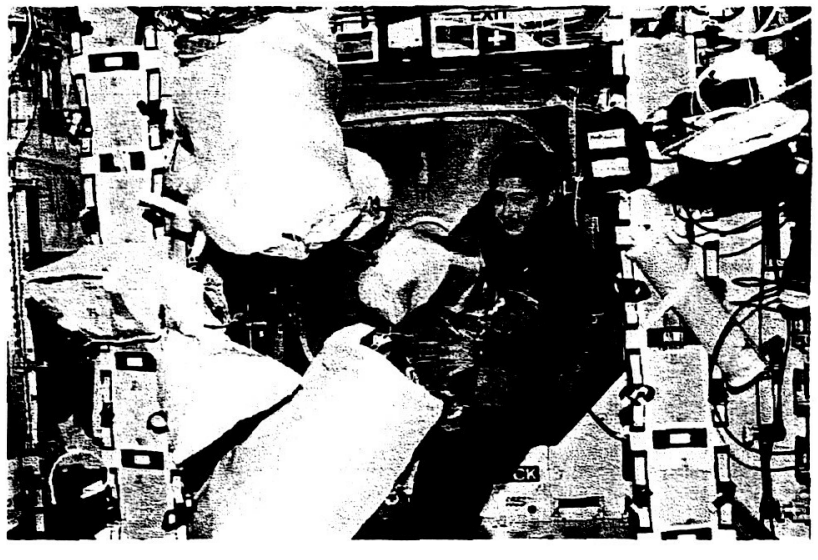

Figure 1. Expedition 4-Flight Engineer Daniel Bursch preparing for an extravehicular activity.

\section{THE BASIC CHALLENGE}

This challenge needs to be approached in a manner that allows the task to be as simple as it is on Earth. That is, after relocating the equipment from the stowed location to the worksite, it stays where you put it. Since there is very low gravity (called microgravity) aboard the ISS, a restraint device or system is needed to provide this condition. This sounds simple but becomes more complex when stated with more detail: temporarily. restrain equipment of various sizes and shapes at random worksite locations within the ISS within arm's reach of the crewmember with quick, easy attachmentand-removal capability of the relocated equipment. This minimizes crew time needed for handling loose equipment (described as loose because it floats away if not restrained). The PERS was developed to accomplish this task/challenge for intravehicular activity aboard the ISS and is documented in the Marshall Space Flight Center (MSFC) reference implementation plan, PERS-PLAN-0034. 
To best solve this problem it is important to understand the overall ISS internal configuration and the typical daily crew operations that involve loose equipment. As the Destiny lab was assembled to the ISS, the worksite capability increased. The lab provides an interface for the several types of international standard payload racks, such as EXPRESS (Expediting the Process of Experiments to Space Station), resupply stowage, and zero-g storage racks. These racks can be located within several of the 24 rack locations, providing a versatile, reconfigurable work environment throughout the lab, as seen in Figure 2. These racks are also equipped with a standard hardware mounting interface, called seat track, used for mounting structural devices, such as handrails, foot restraints, and camera mounts on the front outer face of each rack, as seen in Figure 2. As more of these racks are installed, this seat track interface becomes available throughout the lab in all axes. Therefore, the seat track is an ideal interface for the PERS and provides an enormous variety of mounting locations throughout the U.S. elements. This same interface will also be used in the COF and JEM modules.

\section{ON-ORBIT OPERATIONS}

Daily activities require handling loose equipment and may be executed differently by each crewmember. However, one of the most common aspects is the need to have a variety of equipment, mostly small items and tools, available at arm's reach wherever a crewmember is working, as seen in Figure 2.

A typical crew activity scenario is as follows:

1. Prepare worksite (install crew and equipment restraints).

2. Collect stowed items required to perform the task or procedure and transfer them to the worksite. This may require several trips.

3. Temporarily restrain these items and tools at the worksite.

4. Perform the task without leaving the worksite whenever possible.

This scenario summarizes why a restraint system was needed.

The main goal of PERS is to minimize the overhead required for the crew to handle loose equipment and tools. That is, allow an efficient and effective means for transferring and restraining loose equipment and tools within the microgravity environment. Crew time is critical to operations aboard the ISS. The number of activities the crew can perform in a given day is directly related to the amount of science accomplished. Therefore, it is essential that the crew be provided with the right support equipment to work efficiently. This is accomplished by the following:
- Reduce the number of trips required to and from the worksite and stowage.

- Provide a hands-free transport for small items and tools.

- Provide a means to restrain equipment and tools in a vareity of sizes and shapes at various worksite locations within the ISS.

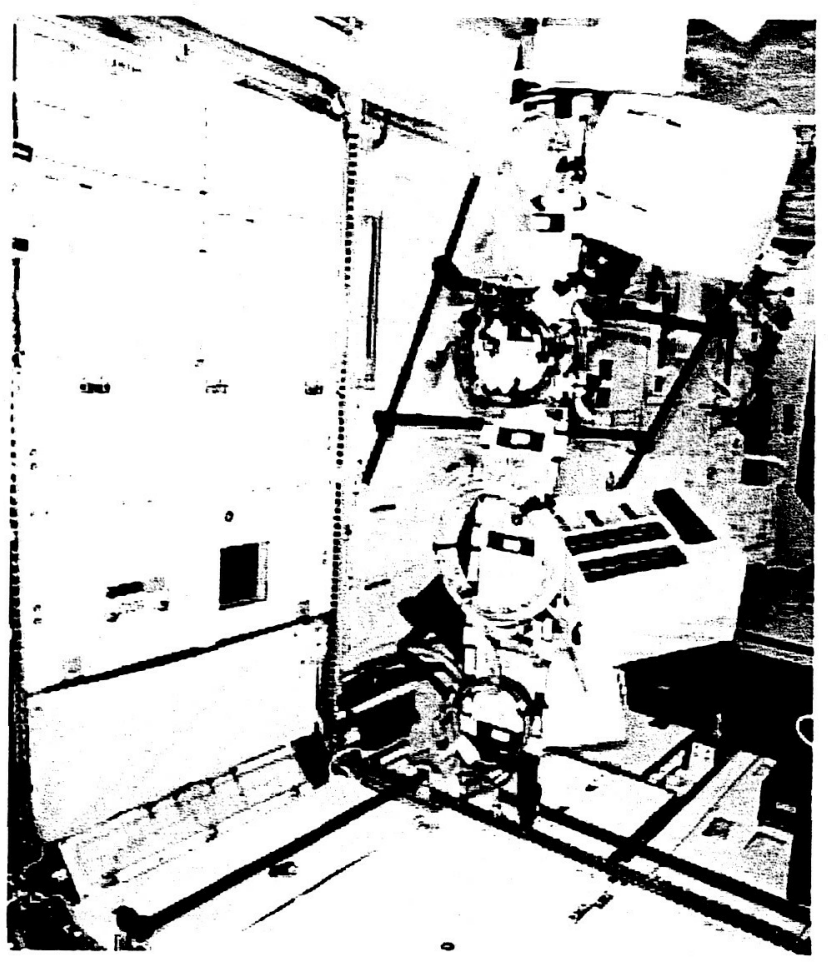

(a)

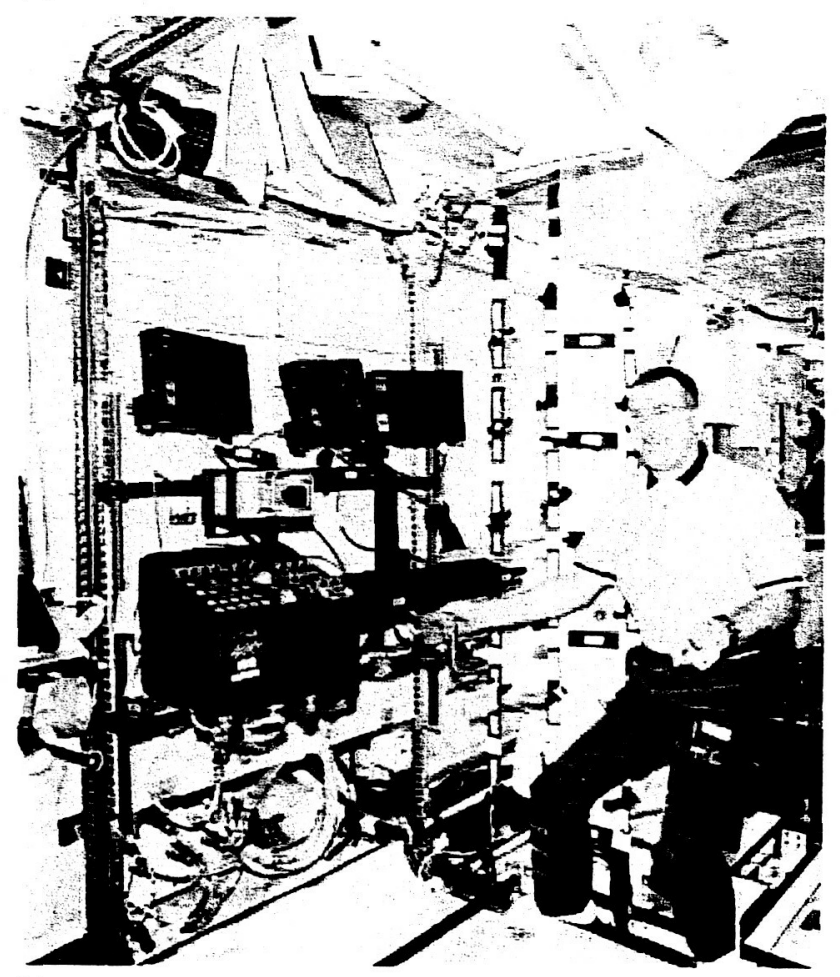

(b)

Figure 2. Robotic workstation (RWS) installation. All equipment is temporarily stowed on the PERS (a) H-Strap, then installed on the (b) seat track. 


\section{DESIGN GOALS}

There were many goals in mind while developing the PERS equipment. One of those goals was to design a restraint system that was intuitive for the crew to understand and operate with little or no training as well as enable crewmembers to use their imaginations for its uses.

The crew was trained on the basic concept of how the PERS equipment could be used as individual elements and as a system. They were also shown how the equipment could be used with other ISS equipment. But as the crew became more familiar with the hardware, it was obvious that they could see its potential uses in ways not previously considered. It was clear that having the crew participate early in the design and evaluate the equipment at various concept stages paid off. Although the original purpose for building this equipment was to support operations for one specific payload, the concept quickly became a generic design that would support many types of Station activities.

Several crewmembers were asked to evaluate the system and provide comments regarding the overall design and how they expected the hardware to perform in microgravity. There were differing comments of how each crewmember would perform a given activity and use the hardware, but there was a common theme in their comments: simplify the design. Some of the original elements of the system had many configurations and multiple uses, and they still do. However, the overall design of the elements was simplified, which contributed to achieving the first goal of making the equipment intuitive to use with little training. In turn, this also simplified the fabrication process to build the equipment-another major goal of the project.

Another design goal was to ensure that PERS would be safe to use within the ISS environment. Proper material selection for efficient use, nontoxic contamination, and flame resistance as well as the structural integrity of the H-Strap and Single Strap were the primary items addressed. The requirements to achieve this goal are documented in the MSFC requirements document, PERS-RQMT-0035A. To ensure that all materials met the ISS requirements, several tests were conducted for both toxic off-gassing and flammability resistance. To ensure that the ISS requirements of structural integrity were met for the Single Strap, several tests were conducted.

The hardware is primarily composed of flame-resistant fabrics and mesh, various types of hook-and-pile fasteners, webbing, buckles, and other off-the-shelf items. By utilizing off-the-shelf materials and hardware, the entire certification, verification, and fabrication process was streamlined, allowing short fabrication times as well as lower overall cost. Since no special equipment is needed to fabricate the hardware, it can easily be done by existing personnel and facilities. Two full-time technicians can fabricate the most complicated items in $\sim 10$ working days. The simpler items can be built in less than 5 working days. This allows for quick fabrication and delivery of the hardware.

Another cost-cutting step was the use of the seat track stud. As mentioned earlier, seat track is the primary interface for mounting equipment in the U.S., ESA, and NASDA modules. Utilizing an existing piece of Station support equipment as the mounting interface for the hardware lowered design and fabrication time and cost, and it also streamlined the certification and verification process required for the ISS interface. The seat track stud, used with other ISS hardware, such as bungees and tethers, is part of the standard ISS flight crew equipment inventory. Since the crew is familiar with this interface and its other uses, this reduced the time for the crew to become familiar with the hardware interface. Again, less crew time required to understand and operate the hardware means more time dedicated to the crew activities themselves.

\section{THE ELEMENTS OF PERS}

The PERS is a five-element, modular system consisting of the following:
1. Belly Pack
2. Tool Pages
3. Laptop Restraint Belt (LRB)
4. Single Strap
5. H-Strap

These elements are designed to allow cohesive crew operations for handling loose equipment. Each of these is described in the following paragraphs.

The Belly Pack serves as a portable stowage volume and interfaces with a crewmember's waist to accommodate hands-free translation to the worksite or may be carried by an adjustable strap. At the worksite, the Belly Pack can be attached to the H-Strap or ISS hook-and-pile fastener surfaces for ease of access. Figure 3 shows the Belly Pack in use aboard the ISS.

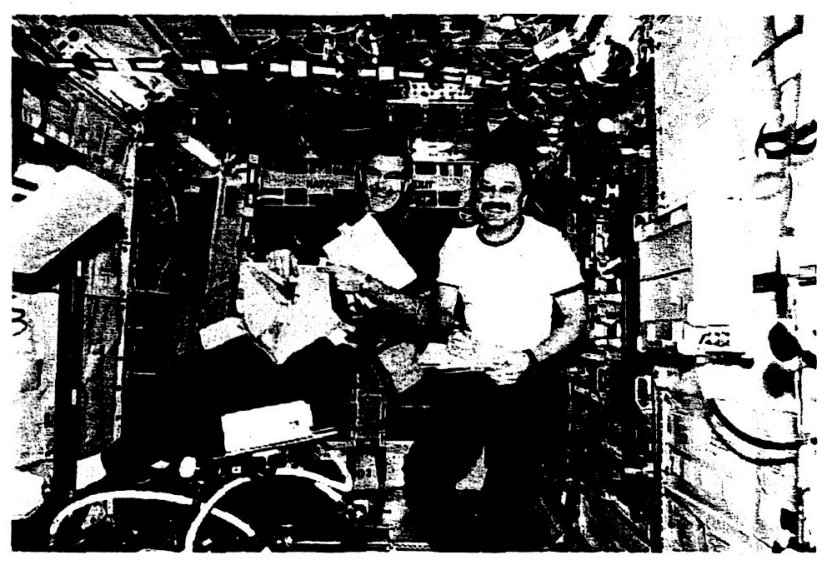

Figure 3. Expedition 2-Flight Engineer Jim Voss (left) wearing the Belly Pack. 
The Tool Pages provide portable containment for restraining tools in an organized fashion and make them readily available to the crew at the worksite. Three types of interfaces are used: hook-and-loop fastener patches, elastic tabs, and standard socket holders. These allow the crew to load the Tool Pages with several different tools as required for any particular task. The Tool Pages are designed to interface with the H-Strap. Figure 4 shows a typical way the Tool Pages are loaded with tools.

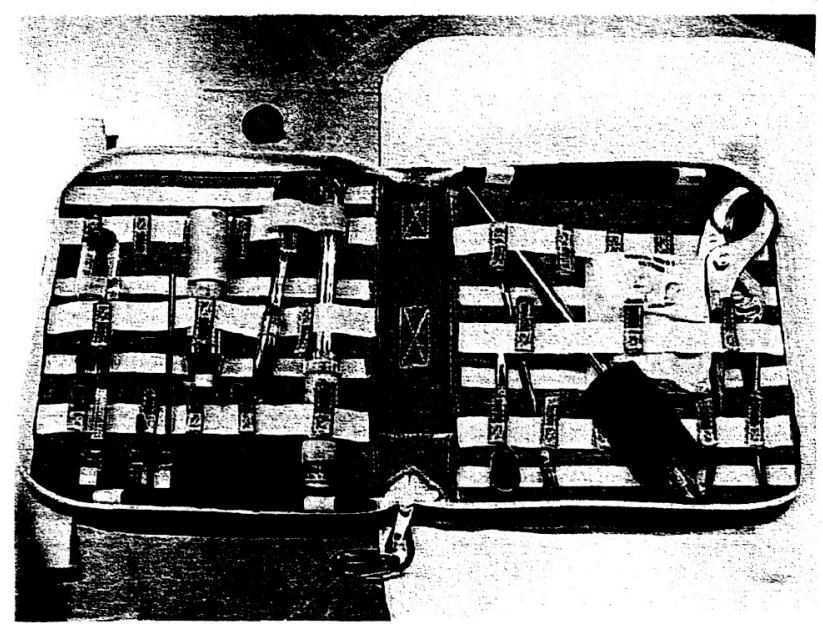

Figure 4. The PERS Tool Pages are used with the ISS tool kits for transporting and temporarily stowing specific tools at the worksite.

The LRB provides a flat surface, which can be deployed on a crewmember's waist and used as a laptop worksurface interface. In addition, the LRB provides bungee interfaces to restrain small tools and equipment. When the LRB is not worn by a crewmember, it can be attached to the H-Strap or other ISS hook-and-pile fastener interfaces and used as a worksurface (Figure 5).

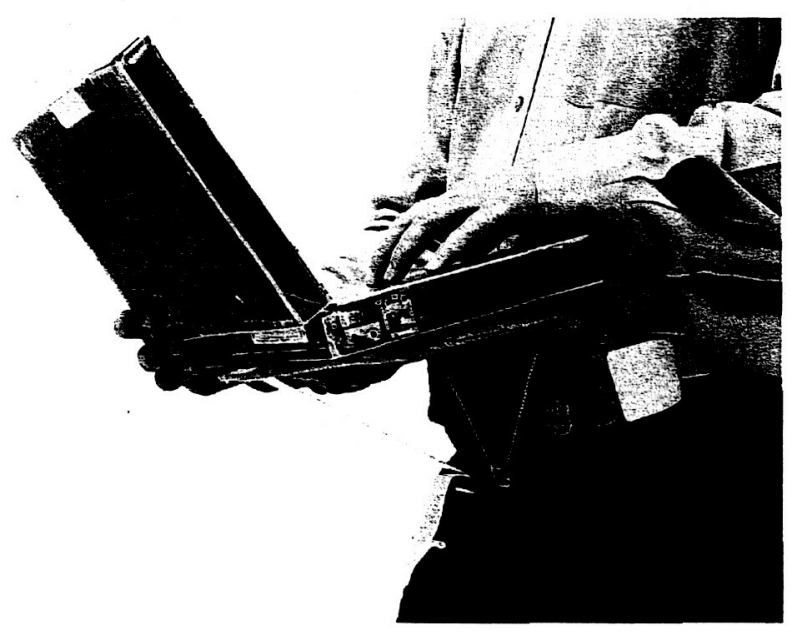

Figure 5. The LRB deployed with the Space Station laptop computer attached to it.
The Single Strap provides temporary restraint/stowage of equipment and tools at the worksite. The Single Strap interfaces to the standard ISS rack seat tracks via the seat track stud. It may be located at a variety of worksites in several configurations depending on the operational requirements. It provides multiple interfaces for restraining equipment and tools: hook-and-pile fasteners, elastic loops, D-rings for bungee/tether use, and integrated ties for cables. Figure 6 shows the Single Strap in use aboard the ISS.

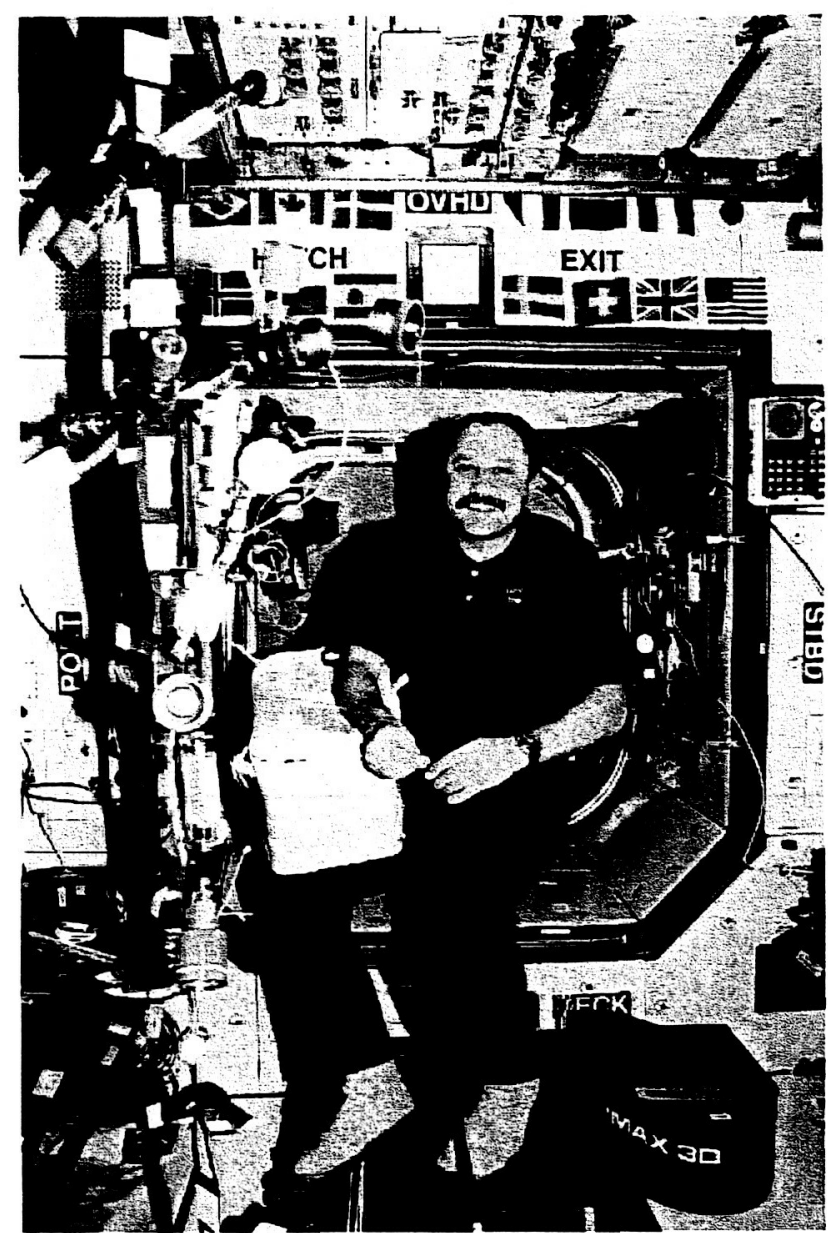

Figure 6. Expedition 2-Commander Yury Usachev using the Single Strap shown in foreground to restrain cables and hoses.

The H-Strap is a portable restraint surface that provides temporary restraint/stowage for equipment and tools at the worksite. The $\mathrm{H}$-Strap also provides restraint interfaces for all of the other PERS elements. In addition to the integrated tool pouches, the H-Strap provides hook-and-pile fastener loops, elastic loops, D-rings, and integrated cable ties to interface with ISS cargo transfer bags (CTBs), bungees/tethers, and other loose equipment. The H-Strap interfaces to the standard ISS rack seat track via seat track studs. Figure 7 shows the H-Strap in use aboard the ISS. 


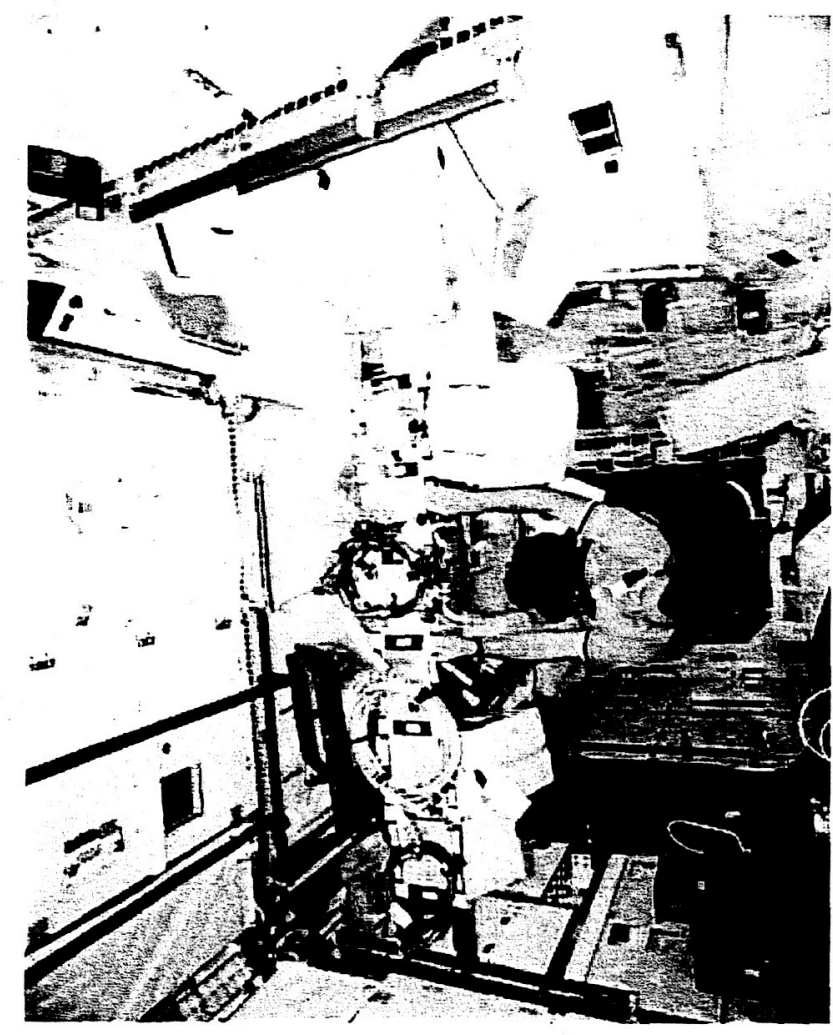

Figure 7. Expedition 2-Flight Engineer Jim Voss preparing to install one of the ISS RWSs.

The PERS elements are also designed to work as an integral system. The Belly Pack, Tool Pages, and LRB interface directly with the H-Strap and Single Strap, as seen in Figure 8.

\section{CONCLUSION (USE ABOARD THE ISS)}

The success of the PERS aboard the ISS was immediate upon arrival. The Expedition 2 crew began using it for multiple tasks and found that it was so useful that some of the PERS items were never put away and remained in constant use on Expeditions 3 and 4. This success is best stated by one of the on-orbit users, astronaut Jim Voss, during some of his debriefing comments: "I think the best thing about the PERS was that it just allowed you to work more efficiently in space. One of the big difficulties of zero-g is keeping everything tied down while you are working with things. PERS solves that problem by allowing you to have all the items close by that you need to work with. We used the PERS straps for everything: large 3.0 CTBs (Figure 9), contingency water containers (CWCs) (Figure 10), big pieces of equipment (Figure 11), hoses and cables (Figure 12), etc. Many of our assembly tasks involved installing multiple (5-15) cables, hoses, and pieces of equipment in bags. We could put all of them near the worksite and not have to make many time-consuming trips back and forth to lockers. We often had what we referred to as 'PERS trees' in the Station-that was when we had multiple objects strapped to a PERS strap and it looked like a tree. We even used them for semilong-term storage of bags when we didn't have a specific stowage location or when we were collecting things for return on an upcoming Shuttle flight. Tool Pages allowed carrying all your tools to a worksite and restrained them there. We used one of them as a permanent toolbox with our most commonly used tools in it, ready to go.

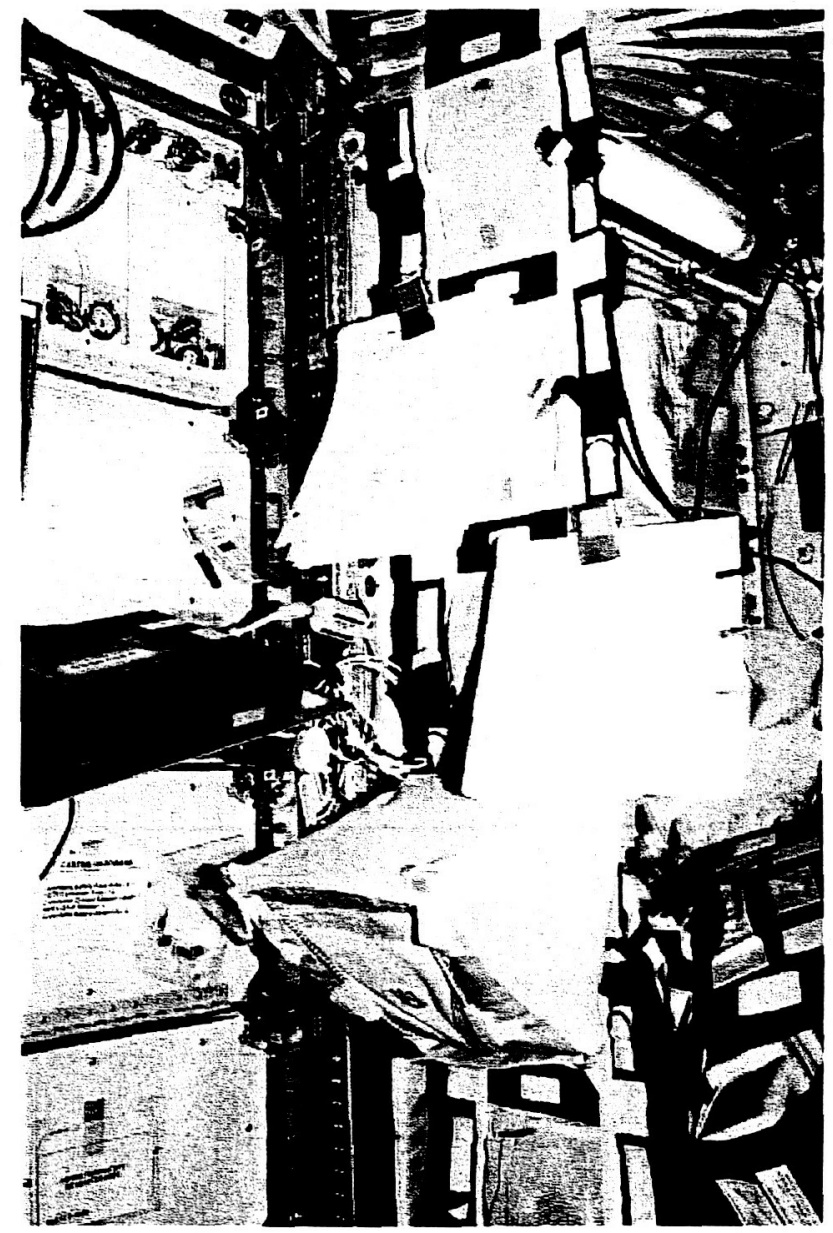

Figure 8. The PERS Belly Pack shown attached to the H-Strap for additional temporarily stowage of various items.

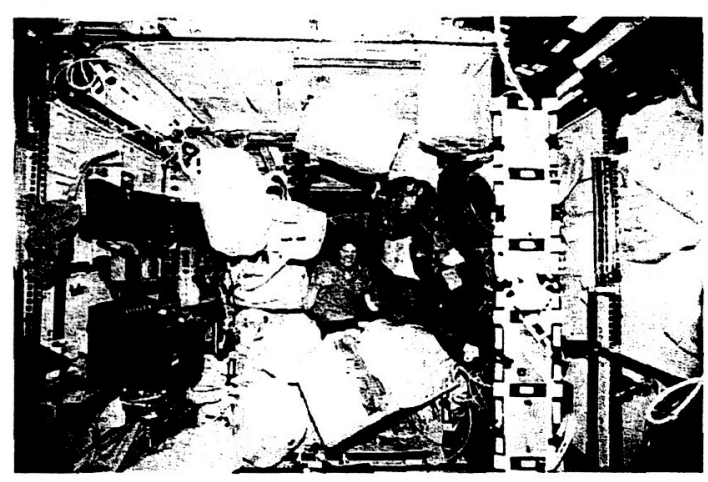

Figure 9. Expedition 2-Flight Engineer Susan Helms shown stowing various large items temporarily on straps. 


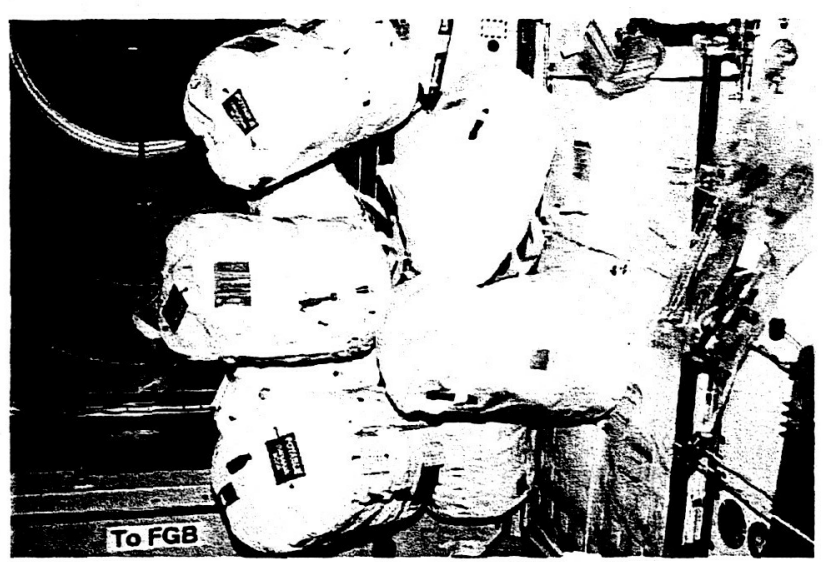

Figure 10. The PERS Single Strap assists in temporarily stowing CWCs.

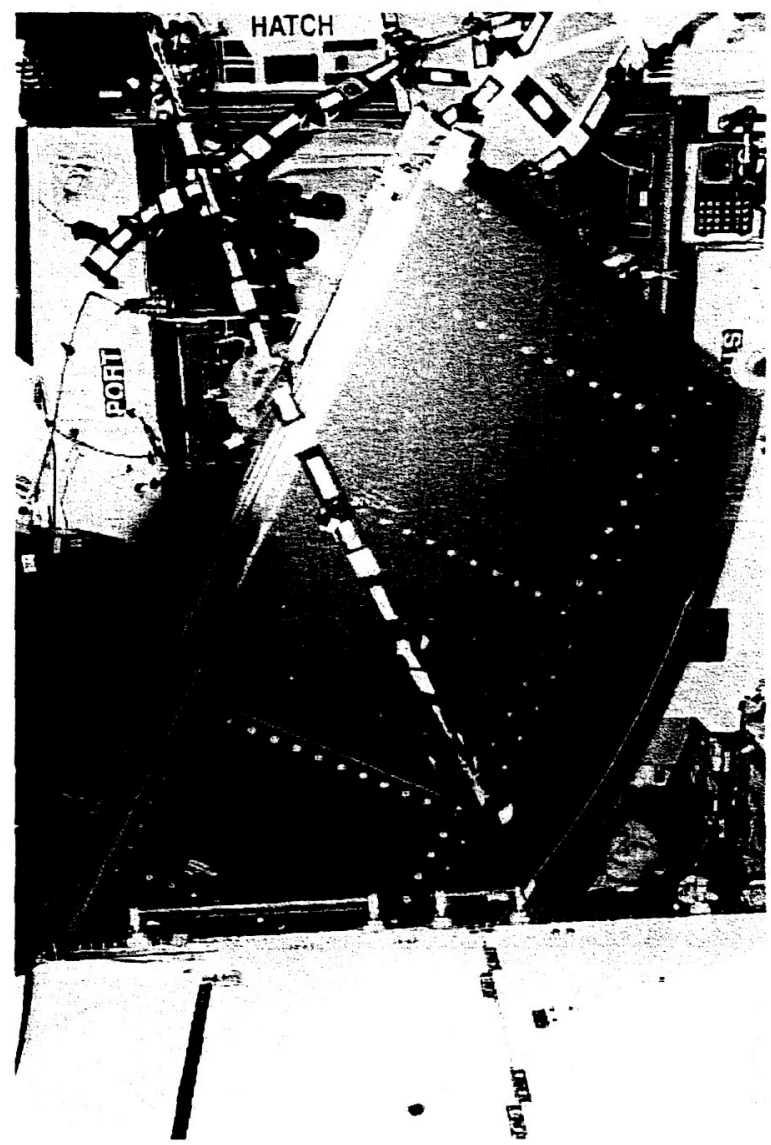

Figure 11. The PERS Single Strap used to restrain a partially rotated rack.

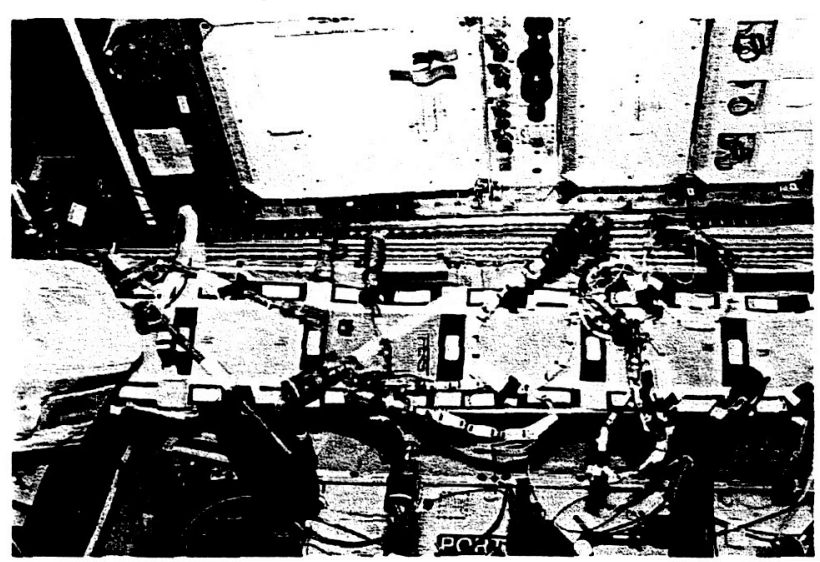

Figure 12. The PERS H-Strap temporarily restrains several cables prior to being installed

We sometimes used PERS straps (using the strap center seat track stud) for holding a rack in a partially rotated position while we worked behind it (Figure 11). And we used it to hold our paper procedures while working (Figure 8 ). Though not designed for this, we often used the straps for handholds and to stop ourselves while moving through the node or lab. I kept my towel, book, and CD player on a strap while I used the CEVIS [Cycle Ergometer Vibration Isolation System] bicycle. Tool Pages were placed on straps near the worksite for ready access to your tools. I used it to hold all the $\operatorname{IMAX}^{\circledR}$ accessories (lenses, cleaning kit, magazine, light meter, lights, cables) near the camera stowage location. I used the strap to restrain the Major Constituents Analyzer [MCA] dryout hose (about 15-ft long, 2.5-in diameter anaconda) when it was connected between vacuum and the MCA. Having a handy, easyto-use restraint system that accommodates all kinds of equipment is a godsend."

These comments sum it up; the challenge was met. The task of restraining loose equipment aboard the ISS is now almost as easy as a similar task on Earth. That is, after relocating the equipment from the stowed location to the worksite, it stays where you put it. This has been accomplished by a simple, easy-to-use system called the PERS. Now almost any size and shape of materials, supplies, tools, and equipment can be easily used at almost any location within the ISS. 